\title{
Ultraviolet-irradiated Monocytes Efficiently Inhibit the Intracellular Replication of Mycobacterium Avium Intracellulare
}

\author{
William S. Mirando, ${ }^{\star}$ Hiroe Shiratsuchi, ${ }^{*}$ Karen Tubesing, ${ }^{\star}$ Hirokazu Toba, ${ }^{\star}$ Jerrold J. Ellner, ${ }^{\star}$ and Craig A. Elmets \\ Departments of ${ }^{*}$ Dermatology and ${ }^{\ddagger}$ Medicine, Case Western Reserve University, Cleveland, Ohio 44106
}

\begin{abstract}
The purpose of this study was to evaluate the effect of ultraviolet (UV) radiation on the antimicrobial activities of monocytes for the intracellular pathogen Mycobacterium avium intracellulare (MAI). UV radiation augmented monocyte antimicrobial activity for MAI in a dose-dependent fashion. UVB doses of $\geq 25 \mathrm{~J} / \mathrm{m}^{2}$ resulted in a 50-100-fold reduction in MAI growth 7 $d$ after initiation of culture. The increased monocyte antibacterial effect could be blocked by a plate glass filter, indicating that wavelengths within the UVB were responsible for the effect. UV radiation did not stimulate monocyte phagocytosis, and enhanced inhibition of MAI growth was observed in populations of adherent mononuclear cells that were devoid of $T$ cells. This suggested that UV radiation acted directly to augment intrinsic monocyte antimicrobial activities. The administration of 8-methoxypsoralen plus UVA radiation to monocytes also augmented their antimicrobial activities against MAI. UV radiation thus may serve as a unique agent by which to evaluate the mechanisms by which mononuclear phagocytes control the growth of MAI. (J. Clin. Invest. 1992. 89:1282-1287.) Key words: ultraviolet radiation - Mycobacteria - macrophage activation $\bullet$ psoralen photosensitivity $\bullet$ monocyte
\end{abstract}

\section{Introduction}

Mycobacterium avium-intracellulare (MAI) ${ }^{1}$ is an endemic faculative mycobacterium that has relatively little virulence for the immunocompetent host $(1,2)$. The organism can cause widespread, disseminated disease involving the lymph nodes, liver, spleen, bone marrow, brain, gut, and skin in individuals with AIDS $(3,4)$ or with hairy cell leukemia $(5,6)$. Involved organs exhibit an abundance of foamy macrophages that contain huge numbers of phagocytosed, but viable, organisms. In AIDS patients, the inability of macrophages to eradicate phagocytosed MAI is thought to be due at least in part to a lack of T lymphocyte-derived cytokines that operate as activating factors $(7,8)$. This, coupled with the fact that infection with MAI

Address correspondence to Craig A. Elmets, M.D., Department of Dermatology, University Hospitals of Cleveland, 2074 Abington Road, Cleveland, OH 44106.

Received for publication 23 January 1991 and in revised form 21 October 1991.

1. Abbreviations used in this paper: 8-MOP, 8-methoxypsoralen; MAI, Mycobacterium avium intracellulare; MN, monocyte; TNF-alpha, tumor necrosis factor-alpha.

J. Clin. Invest.

(c) The American Society for Clinical Investigation, Inc $0021-9738 / 92 / 04 / 1282 / 06 \quad \$ 2.00$

Volume 89, April 1992, 1282-1287 is resistant to most standard antimycobacterial chemotherapeutic regiments $(1,2,9-12)$, has led to a search for alternative methods with which to enhance macrophage antimicrobial activity to MAI.

Incubation of infected macrophages with one or a combination of $T$ cell or non- $T$ cell-derived cytokines has been one approach employed to augment macrophage antimicrobial activity $(8,13)$. In these systems, many organisms have been found to be exquisitely sensitive to the antimicrobial activities of IFN-gamma-activated macrophages (14-18), although other cytokines have been shown to exhibit similar capabilities. In humans, MAI appears to be an exception in this regard (19). Although IFN-gamma has some anti-MAI activity for some strains $(20,21)$, tumor necrosis factor-alpha (TNF-alpha), is the major cytokine known to have activity against MAI in in vitro systems; however, inhibition of MAI growth by this cytokine is relatively modest (22). No other cytokine has been identified that activates macrophages to inhibit the growth of MAI.

Several studies have shown that ultraviolet (UV) radiation is capable of modulating cell-mediated immunological function (for review see reference 23). During the course of studies to determine the influence of UV radiation on immunological effector mechanisms, we observed that UV irradiation of human monocytes (MNs) before infection with MAI was an exceptionally powerful method of activating MNs to limit the growth of this organism.

\section{Methods}

Preparation of monocytes. MNs were obtained by phlebotomy from healthy human volunteers according to the following technique. Peripheral blood was diluted in RPMI 1640 medium and was then layered over a Ficoll-Hypaque (Pharmacia, Inc., Piscataway, NJ) density gradient. After centrifugation, the buffy coat was removed. The mononuclear cells obtained from the buffy coat were resuspended at a density of $1 \times 10^{7}$ cells $/ \mathrm{ml}$ in medium. Three separate 50- $\mu$ l droplets of the cell suspension were plated on $35-\mathrm{mm}$ petri dishes (1008; Falcon Labware, Oxnard, CA) and were allowed to incubate at $37^{\circ} \mathrm{C}$ in a $5 \%$ $\mathrm{CO}_{2}$ incubator for $1.5 \mathrm{~h}$. At the end of this period, the nonadherent cells were removed by aspiration. The remaining adherent cells were $>85 \%$ nonspecific esterase positive. Once the nonadherent cells had been removed, the cells remaining on the petri dishes were exposed to MAI for the phagocytosis and CFU assays. In some experiments, as indicated, cells from the buffy coat were first treated with OKT3 (Ortho Pharmaceutical, Raritan, NJ) and rabbit complement (Pel-Freeze Biologicals, Rogers, AK) before plating to remove residual T lymphocytes.

Inoculation of cultures with MAI. MAI (strain LR542) were cultured in Middlebrook 7H9 broth (Difco Laboratories, Inc., Detroit, MI) according to previously described methods and were frozen until use (19). For infection, cultures were rapidly thawed and sonicated at $475 \mathrm{~W}$ for $10 \mathrm{~s}$ to disperse the Mycobacteria. The organisms, diluted to a density of $1 \times 10^{7}$ organisms $/ \mathrm{ml}$ in RPMI with $5 \%$ autologous serum, were then incubated with cultured MNs for $60 \mathrm{~min}$. The infection medium was then aspirated from the adherent cells. Plates were then washed six times to remove nonphagocytosed organisms. 
UV irradiation of cultures. Four fluorescent FS20 lamps (Westinghouse Electric Corp., Bloomfield, NJ) were used as the irradiation source. The emission spectrum for these lamps is primarily $(60 \%)$ within the UVB (290-320 nm) although there also is significant output within the UVA (320-400 nm) (24). The output of the lamps was monitored with an IL700 research radiometer equipped with an SEE 240 UVB photodetector for UVB radiation. UVB output was measured to be between 1.3 and $1.4 \times 10^{-4} \mathrm{~W} / \mathrm{cm}^{2}$ at a lamp-to-effector cell distance of $21 \mathrm{~cm}$. MNs were irradiated in colorless HBSS. The duration of irradiation ranged from $15 \mathrm{~s}$ for a UVB dose of $10 \mathrm{~J} / \mathrm{m}^{2}$ to $300 \mathrm{~s}$ for a dose of $200 \mathrm{~J} / \mathrm{m}^{2}$. In some experiments, a 4-mm sheet of plate glass was interposed between the lamps and the cells being irradiated. This procedure eliminated $>98 \%$ of the UVB.

For experiments in which cells were exposed to 8-methoxypsoralen (8-MOP) and UVA radiation, the light source was a bank of four high output UVA lamps (HOUVA; National Biological Corporation, Twinsburg, $\mathrm{OH}$ ). Cells were irradiated through both the bottom of the petri dish and a 2-mm glass filter. The UVA output of these lamps was measured to be $5 \times 10^{-3} \mathrm{~W} / \mathrm{cm}^{2}$ at a distance of $4 \mathrm{~cm}$. There was essentially no UVB output. 8-MOP, dissolved in absolute alcohol, was added to cultures immediately before irradiation to achieve a final concentration of $50 \mathrm{ng} / \mathrm{ml}$.

$M N$ antimicrobial activity. This was assessed in a CFU assay using the lysates of infected MN. The method has been described previously (19) and was modified from the method of Crowle et al. (25). Briefly, on days 0,4 , and 7 after infection, separate culture plates containing infected adherent cells were washed extensively to remove extracellular organisms and were frozen at $-70^{\circ} \mathrm{C}$. On day 8 after infection, all plates were thawed and adherent cells were lysed by incubating plates with $0.25 \%$ SDS for $10 \mathrm{~min}$ at room temperature. After the 10 -min incubation period, SDS was neutralized with $0.5 \mathrm{ml}$ of $20 \%$ BSA. Cell lysates were sonicated for $5 \mathrm{~s}$ to disperse MAI. They then were serially 10-fold diluted $\left(10-10^{-3}\right)$ and plated on 7H10 agar (Difco Laboratories, Inc.) in 60-mm petri dishes (1007; Becton Dickinson \& Co., Mountain View, CA). In most instances, three 10- $\mu$ l droplets were placed on the agar at each dilution. Plates were incubated at $37^{\circ} \mathrm{C}$ for $5 \mathrm{~d}$ to obtain visible bacterial colonies. Colonies were counted under a dissecting microscope. Results are expressed as the mean number of CFU $( \pm$ SEM $) / \mathrm{ml}$ of lysate.

Staining procedure for MAI. Immediately after infection, plates were stained to identify Mycobacteria using a Kinyoun acid-fast stain (26). The plates were first fixed with $100 \%$ methanol for $10 \mathrm{~min}$. Then they were stained with Kinyoun stain for $2 \mathrm{~min}$. The plates were rinsed sequentially with $30 \%, 50 \%$, and $70 \%$ ethanol and were then destained with three 1-min washes in acid-alcohol. MNs were counterstained with $0.3 \%$ methylene blue.

Quantitation of phagocytosed mycobacteria. Plates were examined for phagocytosed mycobacteria under oil-immersion light microscopy and the percentage of MNs that contained acid fast bacilli was used to quantify phagocytic activity. At least 200 cells were counted. The average number of AFB/infected cell also was used to quantify phagocytic activity using a slight modification of the method of Douvas and Crowle (27). The number of intracellular mycobacteria per $\mathrm{MN}$ was counted and cells were categorized as having $0,1,2-5,6-12$, or $\geq 13$ organisms per cell. Each category was assigned a value of $0,1,3.5,9$, or 23 , respectively. This value was multipled by the number of MN-phagocytosing bacteria in each of the categories. The sum was then divided by the number of infected cells.

Statistical analysis. The Student's $t$ test was employed for statistical analysis.

\section{Results}

Effect of $U V$ radiation on $M N$ antimicrobial activity for $M A I$. The capacity of UV-irradiated MNs to inhibit the growth of MAI was evaluated by incubating MNs with MAI immediately after UV exposure and then performing CFU assays on lysates of infected cells immediately, 4 , and $7 \mathrm{~d}$ after irradiation. UVirradiated MNs were much more efficient at inhibiting the growth of MAI compared with unirradiated MNs (Fig. 1). Compared with unirradiated MNs, there was a greater than fivefold increase in antimicrobial activity for MAI at a dose of $\geq 25 \mathrm{~J} / \mathrm{m}^{2} 4 \mathrm{~d}$ after infection. This increased to 100 -fold by $7 \mathrm{~d}$. With the exception of $10 \mathrm{~J} / \mathrm{m}^{2}$ on day 7 , the increase in $\mathrm{MN}$ antimicrobial activity was statistically significant at the $P$ $<0.01$ level or greater at all UV dose levels.

Experiments were performed to exclude the possibility that inhibition of MAI growth was caused by accelerated death or injury to UV-irradiated monocytes that disturbed the permissive intracellular environment for growth of the organism. First, cell counts and viability studies were performed on day 0 and day 7 after infection (Tables I and II). There was no greater loss of cells in UV-irradiated cultures than in unirradiated cultures. Furthermore, in all experimental groups viability was always $>95 \%$.

Because the MN preparation used for these assays was only $85 \%$ pure, experiments were performed to determine whether UV radiation augmented $\mathrm{MN}$ antimicrobial activity directly or, alternatively, whether UV radiation augmented T cell-derived cytokine production, which in turn acted on MNs to inhibit MAI growth. Peripheral blood mononuclear cells were first treated with anti-CD3 and complement before adherence to plastic. The addition of this procedure resulted in further enrichment of the $\mathrm{MN}$ population to $>98 \%$ as assessed by nonspecific esterase staining. UV-irradiated $\mathrm{MN}$ preparations treated in this manner retained their ability to inhibit the growth of MAI (Fig. 2), thus indicating that much of the UV-

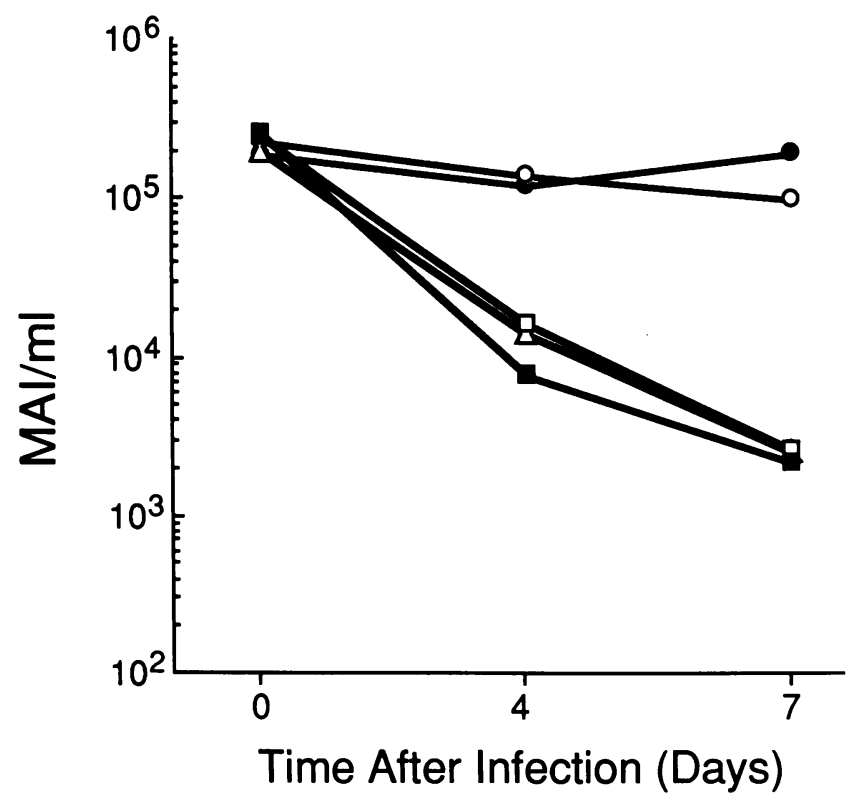

Figure 1. UV-induced dose-dependent increase in MN antimicrobial activity for MAI. MNs were exposed in vitro to varying doses of UV radiation $\left(0-100 \mathrm{~J} / \mathrm{m}^{2}\right)$ and then infected with MAI as described in Methods. The number of viable MAI was determined immediately, 4 , and $7 \mathrm{~d}$ after infection. The increase in $\mathrm{MN}$ antimicrobial activity was significant at the $P<0.01$ level or greater at all UV dose levels with the exception of $10 \mathrm{~J} / \mathrm{m}^{2}$ on day 7 . The data are representative of 5-12 separate experiments. $\longrightarrow, 0 \mathrm{~J} / \mathrm{m}^{2} ; \multimap-10 \mathrm{~J} / \mathrm{m}^{2}$; $\longrightarrow, 25 \mathrm{~J} / \mathrm{m}^{2} ; \longrightarrow-, 50 \mathrm{~J} / \mathrm{m}^{2}, \longrightarrow, 100 \mathrm{~J} / \mathrm{m}^{2}$. 
Table I. Number of UV-treated MNs Immediately after Infection with MAI

\begin{tabular}{rccc}
\hline UV dose & Cell number & $\begin{array}{c}\text { Unirradiated } \\
\text { control }\end{array}$ & Viability \\
\hline$J / m^{2}$ & $\times 10^{6} / \mathrm{mm}^{3}$ & $\%$ & $\%$ \\
0 & 1.58 & - & 97 \\
10 & 1.46 & 92 & 100 \\
25 & 1.37 & 87 & 95 \\
50 & 1.62 & 103 & 97 \\
100 & 1.51 & 96 & 97 \\
200 & 1.59 & 101 & 97 \\
& & & \\
\hline
\end{tabular}

Cells were exposed to UVB radiation, infected with MAI, and examined immediately thereafter for cell number and viability.

induced augmentation in antimicrobial activity against MAI was mediated through a direct effect on the $\mathrm{MN}$ population.

Effect of UV irradiation on phagocytosis of MAI by MNs. The next series experiments examined whether the augmentation in MN antimicrobial activity was associated with an enhanced capacity of UV-irradiated monocytes to phagocytose the organism. In contrast to the augmentation in antimicrobial activities, there was a slight decline in the ability of UV-irradiated monocytes to internalize MAI (Table III). Among those cells capable of internalizing mycobacteria, there was also no difference in the degree of phagocytosis between irradiated and unirradiated cells (Table III).

Additional studies were conducted to evaluate the effect of UV radiation on phagocytosis of MAI. In these experiments, cells were exposed to UV radiation and, rather than infecting them immediately, the cells were placed in culture for varying periods of time. At the end of the culture period, which ranged from 0 to $7 \mathrm{~d}$, the cells were infected with MAI. They then were stained and evaluated for phagocytic activity (Fig. 3, $a$ and $b$ ). MAI phagocytosis was not impaired by UV radiation on days 0 or 7. It should be noted that there was a slight reduction in MAI phagocytosis on days 1 and 2 . However, even at these time points the reduction was relatively minor and, with the exception of $100 \mathrm{~J} / \mathrm{m}^{2}$ on day 1 , was not statistically significant.

Wavelength dependence for $U V$-induced alterations in $M N$ phagocytosis and antimicrobial activity. The fluorescent sunlamps employed for these studies emit UV radiation both in

Table II. Number of UV-treated MNs $7 d$ after Infection with MAI

\begin{tabular}{rccc}
\hline UV dose & Cell number & $\begin{array}{c}\text { Unirradiated } \\
\text { control }\end{array}$ & Viability \\
\hline $\mathrm{J} / \mathrm{m}^{2}$ & $\times 10^{5} / \mathrm{mm}^{3}$ & $\%$ & $\%$ \\
0 & 3.3 & - & - \\
10 & 3.2 & 97 & 100 \\
25 & 3.3 & 100 & 100 \\
50 & 3.2 & 97 & 100 \\
100 & 3.8 & 115 & 100 \\
200 & 2.9 & 88 & 100 \\
\hline
\end{tabular}

Cells were exposed to UVB radiation, infected with MAI, and examined $7 \mathrm{~d}$ later for cell number and viability.

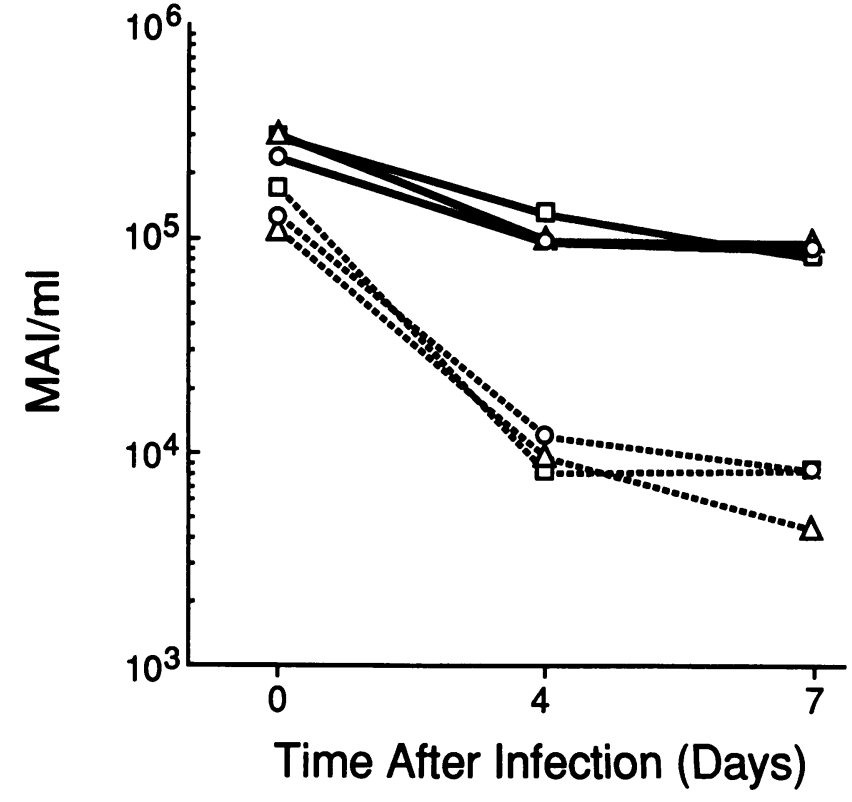

Figure 2. Failure of $\mathrm{T}$ cell depletion to alter the enhanced antimicrobial activity of mononuclear cells for MAI. MNs were left untreated $(\square)$, were treated with complement alone $(\Delta)$, or treated with anti-CD3 plus complement (o). The cells were then infected with MAI and viable MAI were counted as described in Fig. 1. MAI antimicrobial activity of nonirradiated cells (continuous line) was compared with $100 \mathrm{~J} / \mathrm{m}^{2} \mathrm{UV}$-irradiated cells (-- -) by determining the number of viable MAI as described in Methods. Data are representative of two experiments.

the UVA and in the UVB (24). To determine which wavelength bands were responsible for the alterations observed in these studies, 4-mm-thick plate glass was placed between the lamps and the cells being irradiated. This procedure filtered out 98\% of the UVB radiation and reduced emission within the UVA by $27 \%$. Exposure times were lengthened when the plate glass filter was employed to compensate for the reduced amount of UVA emitted. Cells were therefore irradiated with equivalent doses of UVA, but with greatly reduced amounts of UVB. Exposure of MNs to plate glass-filtered UV radiation completely reversed the enhanced capacity of UV-irradiated MNs to inhibit MAI growth (Fig. 4). This indicated that wave-

Table III. MN Phagocytosis of MAI after UVB Exposure

\begin{tabular}{ccc}
\hline UV dose & Cells infected & $\begin{array}{c}\text { Average number } \\
\text { of AFB/infected cell }\end{array}$ \\
\hline$J / m^{2}$ & $\%$ & \\
0 & $46.0 \pm 4.0$ & \\
10 & $45.3 \pm 4.4$ & $4.8 \pm 0.9$ \\
25 & $47.3 \pm 3.4$ & N.D. \\
50 & $47.2 \pm 4.9$ & N.D. \\
100 & $39.8 \pm 2.0^{\ddagger}$ & $5.5 \pm 0.7$ \\
200 & $35.0 \pm 1.4^{\ddagger}$ & $4.5 \pm 1.4$ \\
& & $1.7 \pm 1.2$
\end{tabular}

* Data represent the means \pm SEM of 5-12 experiments at each UV dose level.

₹ Statistically significant at the $P<0.01$ level. 

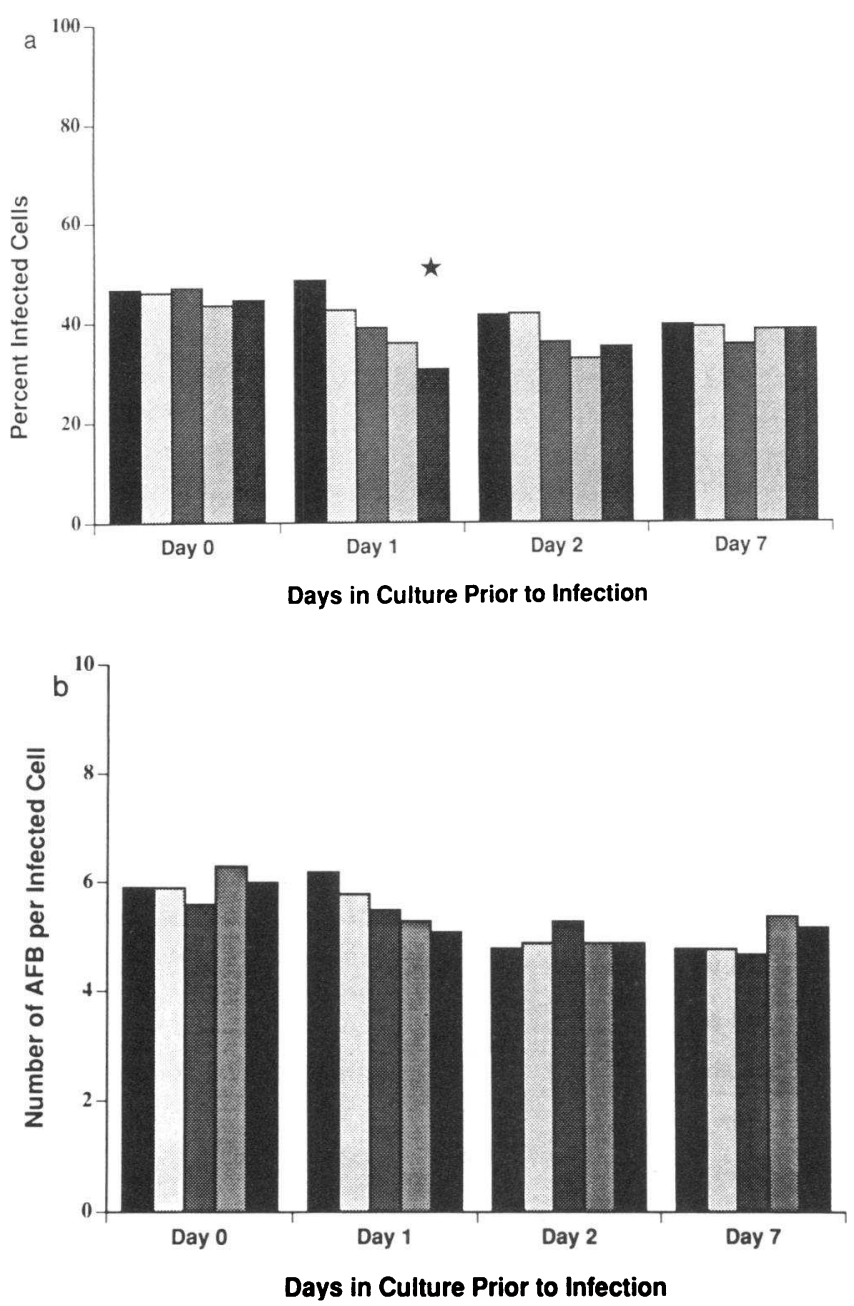

Figure 3. MN phagocytosis of MAI at various times after UVB exposure. MNs were adhered to plastic petri dishes for $1.5 \mathrm{~h}$ and nonadherent cells were removed by gentle pipetting. Cells were UV irradiated and were then placed in culture at $37^{\circ} \mathrm{C}$ for periods of time ranging from 0 to $7 \mathrm{~d}$. At the end of the culture period, cells were infected with MAI. $(A)$ The percentage of cells infected with MAI. $(B)$ The average number of AFB per infected cell. Data are from seven experiments for days 0 and 1 and from three experiments on days 2 and 7. ${ }^{*}$ Statistically significant at the $P<0.05$ level. $\mathrm{m}, 0 \mathrm{~J} / \mathrm{m}^{2} ; \mathrm{B}, 10$ $\mathrm{J} / \mathrm{m}^{2} ; \mathrm{m}, 25 \mathrm{~J} / \mathrm{m}^{2}$, 娄, $50 \mathrm{~J} / \mathrm{m}^{2} ; 100 \mathrm{~J} / \mathrm{m}^{2}$.

length bands within the UVB were responsible for the augmentation $\mathrm{MN}$ antimicrobial activity.

Effect of psoralen photosensitization on $M N$ antimicrobial activity for MAI. Studies were also performed to determine whether the photosensitizing chemical 8-MOP combined with UVA radiation was also capable of enhancing $M N$ antimicrobial activity for MAI. In these experiments, 8-MOP was added to cultures to obtain a final concentration of $50 \mu \mathrm{g} / \mathrm{ml}$. This dose corresponds closely to therapeutic serum concentrations that are present in individuals undergoing psoralen photochemotherapy. 8-MOP-treated cells that were exposed to various doses $\left(1.5-9.0 \mathrm{~J} / \mathrm{cm}^{2}\right)$ of UVA radiation exhibited an enhanced capacity to inhibit the growth of MAI compared with untreated MNs and to MNs treated with 8-MOP alone or UVA alone. However, even at the highest UVA dose, the degree of augmentation was not as great as with UVB-treated monocytes (Fig. 5).

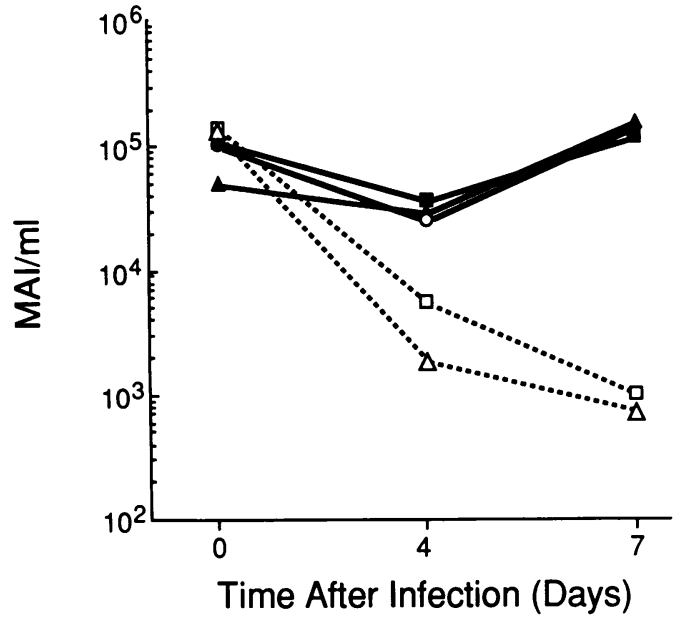

Figure 4. Reversal of the UV-induced augmentation of MN antimicrobial activity for MAI by interposition of a plate glass filter. MNs were exposed in vitro to either filtered or unfiltered UV radiation. Unfiltered UV delivered $100 \mathrm{~J} / \mathrm{m}^{2}$ UVB radiation. The plate glass filter removed $>98 \%$ of the UVB. Exposure times for MNs treated with filtered UV radiation were increased by $30 \%$ to deliver equivalent doses of UVA. The difference between unfiltered and plate glass-filtered MNs was significant at the $P<0.01$ level. Results are representative of three replicate experiments. $-0-0 \mathrm{~J} / \mathrm{m}^{2} ;-$ 一, filtered, $25 \mathrm{~J} / \mathrm{m}^{2} ; \longrightarrow$, filtered, $100 \mathrm{~J} / \mathrm{m}^{2} ; \longrightarrow$, unfiltered, $25 \mathrm{~J} / \mathrm{m}^{2} ; \longrightarrow \square-$ unfiltered, $100 \mathrm{~J} / \mathrm{m}^{2}$.

\section{Discussion}

In the present study, the effect of ultraviolet radiation on the effector function of monocytes for the intracellular pathogen MAI was assessed. UVB radiation produced a mild diminution

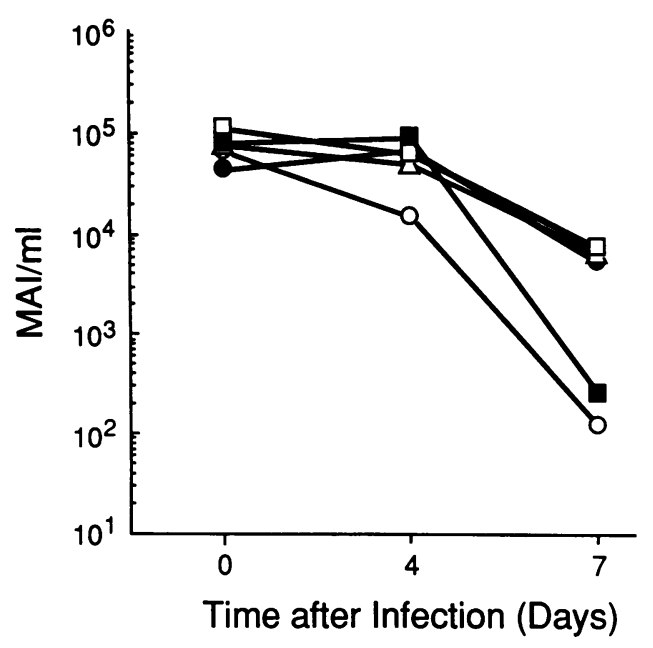

Figure 5. 8-MOP and UVA radiation induced increase in MN antimicrobial activity for MAI. MNs were exposed in vitro to 8-MOP $(50 \mu \mathrm{g} / \mathrm{ml})$ followed by UVA radiation $\left(9.0 \mathrm{~J} / \mathrm{cm}^{2}\right)$ and were then infected with MAI as described in Methods. The number of viable MAI was determined immediately, 4 , and $7 \mathrm{~d}$ after infection. The difference between the control and both UVB and 8-MOP plus UVA was significant at the $P<0.01$ level. The difference between UVB and 8-MOP plus UVA was significant at the $P<0.01$ level at $7 \mathrm{~d}$. The data are representative of three separate experiments. $\rightarrow-$, control; $\multimap, \mathrm{UVB} ; \multimap-, 8-\mathrm{MOP} ; \multimap-$ UVA; $\rightarrow-, 8-\mathrm{MOP}+\mathrm{UVA}$. 
in monocyte phagocytosis of the organism, which was more than compensated for by a 100-fold enhancement in antimicrobial activity. These findings are noteworthy because of the paucity of agents known to limit the growth of this organism (1, 2, 9-12). TNF-alpha, the only other agent known to inhibit MAI growth, was at best only able to inhibit the growth of MAI by a factor of two in in vitro systems (22). This makes UVB the most effective agent known to promote $\mathrm{MN}$ antimicrobial activities against MAI. It should be noted that monocytes were not infected with organisms until after they had been UV irradiated. Therefore, in these experiments the inhibitory effect on MAI proliferation could only have been mediated indirectly through its effect on monocytes. This indicates that under the right conditions mononuclear phagocytes can be activated to inhibit the growth of MAI.

The effect of UVB radiation was selective and was not caused by a nonspecific damaging effect on the monocyte population interfering with the intracellular milieu conducive to growth of the intracellular parasite. The number and viability of UV-irradiated monocytes were no different at the initiation or at the end of culture compared with the unirradiated monocyte population. Furthermore, there was no difference between the phagocytic capacity of UV-irradiated and unirradiated MNs after $7 \mathrm{~d}$ of culture. Finally, the number of MAI CFUs, when placed in culture medium alone without monocytes was unchanged over a 7-d culture period (unpublished data). This is in contrast to the marked reduction in the number of MAI CFUs obtained when UV-irradiated monocytes were allowed to phagocytose the organism and CFUs were prepared. It should also be emphasized that, under normal conditions, MAI grows slowly in macrophages. Thus, it is unlikely that the observed 100-fold reduction in MAI growth was caused by the inability of the organism to grow within the macrophage, but rather was due to killing of the organism by the UV-irradiated monocyte.

Because of the potential for stratospheric ozone depletion to augment the amount of UVB radiation reaching the earth's surface, most recent investigation has focused on the adverse effects of UV radiation on immunological function. For example, UVB exposure inhibits the accessory function of human monocytes for antigen- and mitogen-induced $T$ cell blastogenesis $(28,29)$. The decline in monocyte accessory function is associated with a reduction in monocyte ICAM-1 expression $(29,30)$, a molecule, whose presence on the cell surface is essential for T cell-monocyte interactions and $\mathrm{MN}$ accessory activities. UV radiation has also been shown to have a deleterious effect on the course of certain experimental infections $(31,32)$. In a recent article using a murine model of Mycobacterium bovis infection, large doses of UV radiation were delivered to a skin site remote from the site of infection. UV radiation was shown to transiently suppress delayed type hypersensitivity to the organism (31). This was followed by an increase in mycobacterial proliferation. Although this may at first appear to contradict our findings, it should be noted that much larger doses of UV radiation were employed and they were delivered in vivo to an area of skin distant from the site of infection. Other investigators have examined the effect of smaller doses of UV radiation in a murine model of cutaneous leishmaniasis (33). In those studies, UV radiation exposure was accompanied by healing of the cutaneous disease but without clearing of the organism. The difference between this study and ours may re- flect differences in the immunopathogenic mechanisms by which these organisms are eradicated $(34,35)$.

Of considerable interest is the mechanism by which UVB radiation augments monocyte MAI antimicrobial activities. Recent studies have demonstrated that large doses of 1,25-dihydroxyvitamin $\mathrm{D}_{3}$ is a potent inhibitor of the growth of $\mathrm{Myco}$ bacterium tuberculosis $(36,37)$. Ultraviolet radiation plays a fundamental role in the vitamin $\mathrm{D}$ metabolic pathway converting provitamin $\mathrm{D}_{3}$ to previtamin $\mathrm{D}_{3}(38)$. It is also capable of converting 25-hydroxyvitamin $\mathrm{D}_{3}$ to 1,25-dihydroxyvitamin $\mathrm{D}_{3}$ in the U937 monocytoid cell line (39). One possible mechanism by which UV radiation acts may be to increase the production of vitamin D-dependent metabolites, which in turn could inhibit MAI growth.

UV radiation also triggers the synthesis of a select group of proteins within cells (40). These include TNF-alpha, metallothionein, and collagenase. With the exception of TNF-alpha, there is currently no evidence that any of these proteins has antimycobacterial effects. It is nevertheless possible that one of these proteins is directly responsible for the augmented MAI killing by UV-irradiated MNs.

In other studies, we have shown that UV radiation inhibits MN production of IL-1 (28). We have also recently shown that IL-1 promotes MAI growth in culture (21). Thus, another possible mechanism by which UV radiation acts to inhibit MAI growth is by impairing production of this cytokine. However, for the reasons stated above, this is unlikely to be the only mechanism by which UV radiation inhibits MAI growth

Because the depth of penetration of UV radiation reaches only into the superficial dermis, it is unlikely that UVB or psoralen plus UVA phototherapy could be employed as a therapeutic agent for MAI infections. However, this form of radiant energy may serve as a useful tool for further investigation into the mechanisms by which mononuclear phagocytes control MAI growth. Furthermore, if UV radiation has similar antimicrobial activities against other intracellular pathogens, it may be possible to employ this form of radiant energy to treat those mycobacterial infections, such as leprosy, which are localized to the skin. It should be noted that the use of UV radiation for the control of infectious diseases is not without precedent, as it was at one time used to treat lupus vulgaris, a form of cutaneous tuberculosis (41).

\section{Acknowledgments}

We thank Carol Highsmith for her excellent secretarial assistance.

This work was supported by grants from the National Institutes of Health (AR32593, AR39750, and AI25799). Dr. Elmets is the recipient of a National Institutes of Health Research Career Development Award.

\section{References}

1. Rosensweig, D. Y. 1979. Pulmonary mycobacterial infections due to $M y c o$ bacterium intracellulare-avium complex: clinical features and course in 100 consecutive cases. Chest. 75:115-119.

2. Wolinsky, E. 1979. Nontuberculous mycobacteria and associated diseases. Am. Rev. Respir. Dis. 119:107-159.

3. Zokowski, P., S. Fligiel, G. W. Berlin, and B. L. Johnson, Jr. 1982. Disseminated Mycobacterium avium-intracellulare infection in homosexual men dying of acquired immunodeficiency. J. Am. Med. Assoc. 248:2980-2982.

4. Hawkin, C. C., J. W. M. Gold, E. Whimbey, T. E. Kiehn, and P. Brannon. 1986. Mycobacterium avium complex infections in patients with the acquired immunodeficiency syndrome. Ann. Intern. Med. 105:184-188. 
5. Gallo, J. H., G. A. R. Young, and P. R. Forest. 1983. Disseminated atypical mycobacterial infection in hairy-cell leukaemia. Pathology. 15:241-245.

6. Weinstein, R. A., H. M. Golomb, and G. Grumet. 1981. Hairy-cell leukemia: association with disseminated atypical mycobacterial infection. Cancer (Phila.). 48:380-383.

7. Murray, H. W., B. Y. Rubin, H. Masur, and R. B. Robert. 1984. Impaired production of lymphokines and immune (gamma) interferon in the acquired immunodeficiency syndrome. N. Engl. J. Med. 310:883-889.

8. Murray, H. W., R. A. Gellene, D. M. Kibby, C. D. Rothermil, and B. Y. Rubin. 1985. Activation of tissue macrophages from AIDS patients: in vitro response of AIDS alveolar macrophages to lymphokines and interferon-gamma. J. Immunol. 135:2374-2377.

9. Etzkorn, E. T., S. Aldarondo, C. K. McAllister, J. Matthews, and A. J. Oznibene. 1986. Medical therapy of Mycobacterium avium-intracellulare pulmonary disease. Am. Rev. Respir. Dis. 134:442-445.

10. Ahn, C. W., S. S. Ahn, R. A. Anderson, D. T. Murphy, and A. Mammo. 1986. A four-drug regimen for initial treatment of cavitary disease caused by Mycobacterium avium complex. Am. Rev. Respir. Dis. 134:438-441.

11. Davidson, P. T., V. Khanijo, M. Goble, and T. S. Moulding. 1981. Treatment of disease due to Mycobacterium intracellulare. Rev. Infect. Dis. 3:10521059.

12. Dutt, A. K., and W. H. Stead. 1979. Long-term results of medical treatment in Mycobacterium intracellulare infection. Am. J. Med. 67:449-453.

13. Murray, H. W. 1988. Interferon-gamma, the activated macrophage, and host defense against microbial challenge. Ann. Intern. Med. 108:595-608.

14. Nathan, C. F., H. W. Murray, M. E. Weibe, and B. Y. Rubin. 1983. Identification of interferon-gamma as the lymphokine that activates human macrophage oxidative metabolism and antimicrobial activity. J. Exp. Med. 158:670689.

15. Rothermel, C. D., B. Y. Rubin, and H. W. Murray. 1983. Gamma-interferon is the factor in lymphokine that activates human macrophages to inhibit intracellular Chlamydia psittaci replication. J. Immunol. 131:2542-2544.

16. Murray, H. W., B. Y. Rubin, and C. D. Rothermel. 1983. Killing of intracellular Leishmania donovani by lymphokine-stimulated human mononuclear phagocytes. J. Clin. Invest. 72:1506-1510.

17. Passwell, J. H., R. Shor, and J. Shoham. 1986. The enhancing effect of interferon-beta and gamma on the killing of Leishmania tropica major in human mononuclear phagocytes in vitro. J. Immunol. 136:3062-3066.

18. Bhardwaj, N., T. W. Nash, and M. A. Horwitz. 1986. Interferon-gammaactivated human monocytes inhibit the intracellular multiplication of Legionella pneumophilia. J. Immunol. 137:2662-2669.

19. Toba, H., J. T. Crawford, and J. J. Ellner. 1989. Pathogenecity of Mycobacterium avium for human monocytes: absence of macrophage-activating factor activity of gamma interferon. Infect. Immun. 57:239-244.

20. Johnson, J. L., H. Shiratsuchi, H. Toba, and J. J. Ellner. 1991. Preservation of monocyte effector functions against Mycobacterium avium-M. intracellulare in patients with AIDS. Infect. Immun. 59:3639-3645.

21. Shiratsuchi, H., J. L. Johnson, and J. J. Ellner. 1991. Bidirectional effects of cytokines on the growth of Mycobacterium avium within human monocytes. $J$. Immunol. 146:3165-3170.

22. Bermudez, L. E. M., P. Stevens, P. Kolonoski, M. Wu, and L. S. Young 1989. Treatment of experimental disseminated Mycobacterium avium complex infection in mice with recombinant IL-2 and tumor necrosis factor. J. Immunol. 143:2996-3000

23. Krutmann, J., and C. A. Elmets. 1988. Recent studies on mechanisms in photoimmunology. Photochem. Photobiol. 48:787-798.

24. Task Force on Photobiology. 1974. Report on ultraviolet light sources. Arch. Dermatol. 109:833-839.

25. Crowle, A. J., J. A. Sbarbaro, F. N. Judson, G. S. Douvas, and M. May. 1984. Inhibition by streptomycin of tubercle bacilli within cultured human macrophages. Am. Rev. Respir. Dis. 130:839-844.

26. Lennette, E. H., E. H. Spaulding, and J. P. Truant, editors. 1974. Manual of Clinical Microbiology. 2nd ed. American Society for Microbiology, Washington, DC, p. 945.

27. Douvas, G. S., and A. J. Crowle. 1985. Macrophages as a model for studying antimicrobial immunity in vitro. In Investigation of Cell-mediated Immunity. T. Yoshida, editor. Churchill Livingstone, Inc., New York. 81-90.

28. Rich, E., C. A. Elmets, H. Fujiwara, R. S. Wallis, and J. J. Ellner. 1987. Deleterious effect of ultraviolet-B radiation on accessory function of human blood adherent mononuclear cells. Clin. Exp. Immunol. 70:116-126.

29. Krutmann, J., I. U. Khan, R. S. Wallis, F. Zhang, E. A. Rich, J. J. Ellner, and C. A. Elmets. 1990. Cell membrane is a major locus for ultraviolet-B-induced alterations in accessory cells. J. Clin. Invest. 85:1529-1536.

30. Hertl, M., D. R. Kaplan, J. D. Fayen, J. R. Panuska, J. J. Ellner, and C. A. Elmets. 1991. The accessory function of B lymphocytes is resistant to the adverse effects of UV-radiation. Eur. J. Immunol. 21:291-297.

31. Jeevan, A., and M. L. Kripke. 1989. Effect of a single exposure to ultraviolet radiation on Mycobacterium bovis bacillus calmette-guerin infection in mice. J. Immunol. 143:2837-2843.

32. Denkins, Y., I. J. Fidler, and M. L. Kripke. 1989. Exposure of mice to UVB radiation suppresses delayed hypersensitivity to Candida albicans. Photochem. Photobiol. 49:615-619.

33. Giannini, M. S. H. 1986. Suppression of pathogenesis in cutaneous Leishmaniasis by UV radiation. Infect. Immun. 51:838-843.

34. Ellner, J. J., and R. S. Wallis. 1989. Immunologic aspects of mycobacterial infections. Rev. Infect. Dis. 11(Suppl. 2):S455.

35. Muller, I., T. Pedrazinni, J. P. Farrell, and J. Louis. 1989. T-cell responses and immunity to experimental infection with Leishmania major. Annu. Rev. Immunol. 7:561-578.

36. Rook, G. A. W., J. Steele, L. Fraher, S. Barker, R. Karmali, and J. O. Riordan. 1986. Vitamin D3, gamma interferon, and control of proliferation of Mycobacterium tuberculosis by human monocytes. Immunology. 57:159-163.

37. Crowle, A. J., E. J. Ross, and M. H. May. 1987. Inhibition by $1,25-(\mathrm{OH})_{2-}$ vitamin D3 of the multiplication of virulent tubercle bacilli in cultured human macrophages. Infect. Immun. 55:2945-2950.

38. Webb, A. R., and M. F. Holick. 1988. The role of sunlight in the cutaneous production of vitamin D3. Annu. Rev. Nutr. 8:375-399.

39. Adams, J. S., and C. A. Elmets. 1990. Interactive influence of ultraviolet $B$ radiation and vitamin $\mathrm{D}$ on human immune cells. Clin. Res. 38:117A. (Abstr.)

40. Stein, B., H. J. Rahmsdorf, A. Steffen, M. Litfin, and P. Herrlich. 1989. UV-induced DNA damage is an intermediate step in UV-induced expression of human immunodeficiency virus type I, collagenase, c-fos and metallothionein. Mol. Cell. Biol. 9:5169-5181.

41. Finsen, N. R. 1901. Phototherapy. Edward Arnold, London, 142 pp. 